\title{
La preescolarización del niño en la educación pública colombiana (1960-1994)*
}

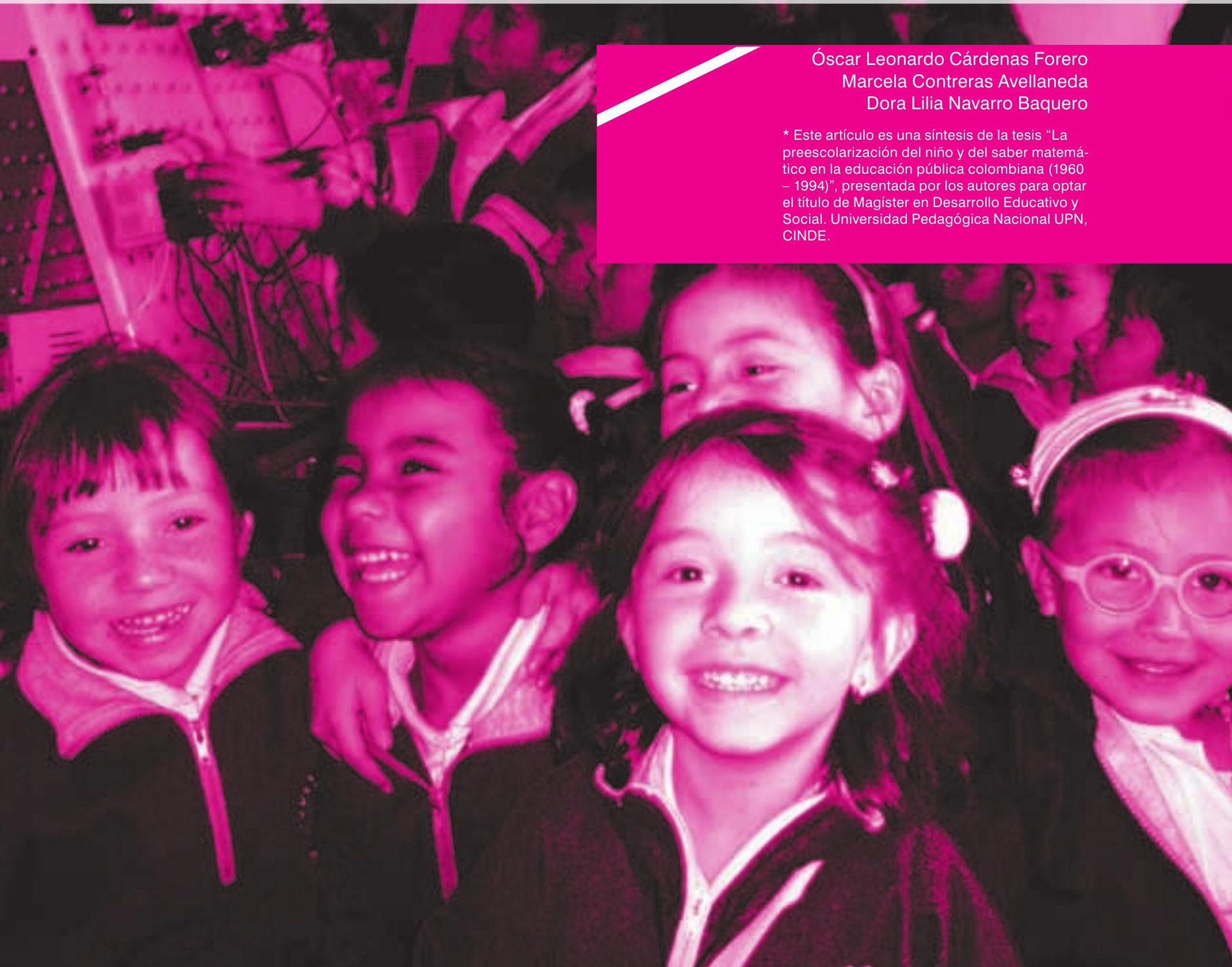




\section{Resumen}

El presente artículo enmarcado en el enfoque arqueológico-genealógico propuesto por Michel Foucault, tiene como propósito rastrear y describir las condiciones y líneas de fuerza que se entrecruzaron para posibilitar la aparición de una nueva forma de escolarización del niño en la educación pública colombiana en el período 1960-1994. Con ello, se pretende mostrar cómo la "preescolarización infantil" fue el resultado de un complejo proceso de enfrentamiento, despliegue y establecimiento de relaciones de saber-poder, discursos, instituciones, saberes, controles y prácticas. Pero además, es un intento por superar la intención de indagar en el pasado el origen de los acontecimientos; es más bien, una apuesta por conformar el esquema de circunstancias que hicieron posible la preescolarización de la infancia y su configuración como dispositivo de poder dentro de la escuela y la sociedad. Por tanto, el objeto que enmarca este artículo, gira en torno a cómo estas nuevas prácticas de subjetivación que se fueron instituyendo, configuraron nuevas subjetividades infantiles preescolarizadas que en algún momento fueron "fenómenos curiosos", pero que hoy día han dejado de ser extraños y hacen parte de lo que se enuncia y legitima de manera consustancial en la sociedad.

\section{Palabras claves}

Preescolarización, subjetivación escolar, niñez, escuela primaria, educación pública colombiana.

\section{Abstract}

This article framed in the archaeological and genealogical approach proposed by Michel Foucault aims to trace and describe the conditions and power lines that intersect to enable the emergence of a new form of schooling of children in public education in Colombia during the period $1960-1994$. Thus, it is intended to show how the "child pre-schooling" was the result of a complex process of engagement, deployment and establishment of relations of knowledge - power, speeches, institutions, knowledge, controls and practices. But also, it is an attempt to overcome the intent to investigate the origin of past events; it is rather, a commitment to confront the pattern of circumstances that made possible the preschooling of children and its configuration as a power device in school and society. Therefore, the object that frames this article, goes around how these new subjectivation practices that were instituted, shape new subjectivities pre-schooling children that at times were curious phenomenon, but today are no longer strangers and make part of what is lawful otherwise stated and inherent in society.

\section{Key words}

Pre-schooling, subjectivities pre-schooling, children, primary school, public education in Colombia.

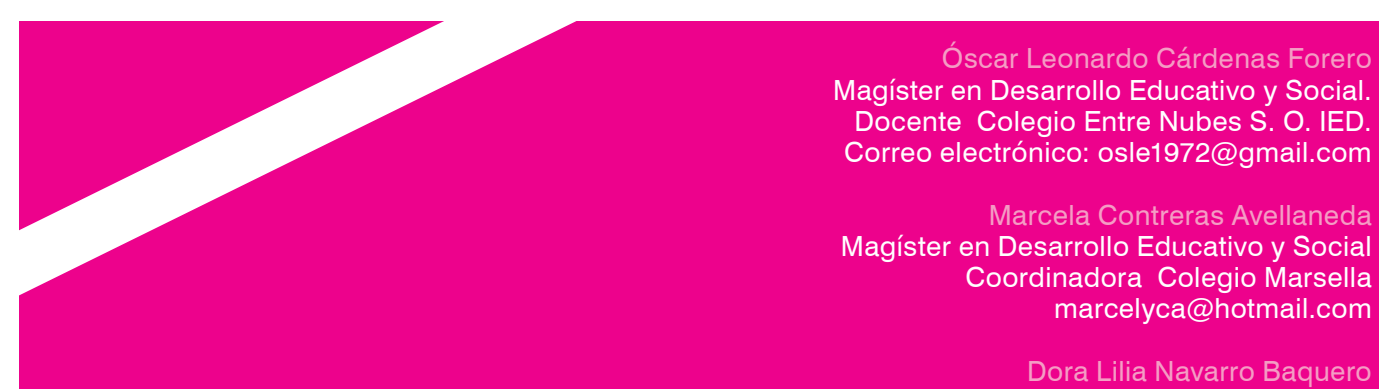

Magíster en Desarrollo Educativo y Social.

Docente Colegio Departamental PIO X, Chipaque (Cundina-

doranaba@hotmail.com

Fecha de recepción: Septiembre 7 de 2011 Fecha de aprobación: Octubre 19 de 2011 


\section{Exordio de una sospecha}

Las reflexiones aquí desplegadas son un inesperado recorrido por lugares insospechados de la historia en los que se ponen en evidencia juegos de poder, prácticas de saber y líneas de fuerza que promueven la constitución de nuevas subjetividades, realidades y territorios de indagación hasta el momento, perdidos o borrados. Con ellas se comprende que los acontecimientos históricos, no son simples hechos que suceden, sino más bien rupturas, "fenómenos curiosos", quiebres o irrupciones que anteceden a un cambio en el marco social establecido. En esta perspectiva, no se trata entonces, de ir tras el rastro de lo «eterno» sino de la emergencia, de la procedencia, de lo que irrumpe para transformar, de aquello que es nuevo en determinada época, que fractura la conexión lineal que se ha dibujado durante largo tiempo con el pasado, para "desenmascarar las relaciones de poder que controlan el cuerpo social" (Álvarez-Uría, F. \& Varela, 1999: 29).

Así, con esta nueva tendencia histórica lo que se pretende es ir tras las huellas de un acontecimiento en particular, la preescolarización del niño en la educación pública colombiana entre 1960 y 1994, en el que se describe el declive de una niñez escolarizada instituida, que hasta ese momento era considerada como un cuerpo infantil dócil, maleable, manipulable, disciplinado, rígido, obediente, subordinado y heterónomo, asociada con "la idea de (...) fragilidad, (...) debilidad y (...) vulnerabilidad. La mirada que se hizo de la infancia en ese entonces partía del supuesto de que en esa edad se estaba más expuesto a ser influenciado o a ser afectado por el mundo externo. Un ser frágil, fácilmente quebrantable [que] debía ser sobre todo defendido de las malas influencias del mundo, protegido de cualquier amenaza" (Álvarez, 2002: 10), para permitir la instalación, hoy día, de una nueva subjetividad escolar activa, autónoma, flexible, participativa, con capacidades intelectuales, afectivas, comunicativas, enmarcadas en una perspectiva del desarrollo integral armónico y multidimensional, con diversos aprendizajes, habilidades y destrezas, que de la mano de la «integralidad», del «desarrollo de las dimensiones humanas» y el empleo de mecanismos, como el juego y la manipulación de objetos (bloques lógicos, rompecabezas, juegos didácticos, loterías, palos de paleta, botones, regletas) y saberes escolarizados, incursionan para impeler una manera distinta de ser sujeto escolar que interviene como un acontecimiento para romper con lo establecido, con lo que estaba ocurriendo de manera habitual y era admitido en la vida social, escolar y educativa. Con esto, lo que se pretende es "describir una mirada, una manera de pensar acerca de la infancia, [de cómo] unos supuestos dados (...) se convierten en verdades que le dan el estatuto de sujeto histórico a una edad como la de la infancia" (Álvarez, 2002: 3), es decir, de cómo en un momento determinado, como producto del enfrentamiento de múltiples líneas de fuerza, se construyó una nueva imagen de infancia en la escuela, de escolarización infantil, de control sobre la niñez, que hoy se muestra como si siempre hubiese estado allí, inmersa de manera natural en la institución educativa, sin detenerse a indagar de qué modo y en qué momento la preescolarización de los niños se fue configurando como una condición de socialización y formación previa al ingreso a la escuela primaria.

\section{De las condiciones que hicieron posible la preescolarización de la infancia}

\section{"Muchos niños sin educación": La Democratización}

Durante la década de los sesenta del siglo XX en Colombia, la preescolarización del niño no era un asunto de preocupación en la vida social, ya que la familia asumía las prácticas de disciplinamiento temprano y el Estado declaraba que la educación pública primaria se consideraba como "la etapa inicial del proceso educativo, a la que toda persona, sin discriminación alguna, [tenía] derecho a partir de los siete (7) años de edad" (Decreto 1710 de 1963). De este modo, la escuela primaria se configuraba en la sociedad como la primera forma de institucionalización y escolarización infantil, el paso preliminar del hogar a la escuela, en la que el niño adquiría la denominación de «escolarizado», susceptible de continuar siendo normalizado, habituado a las condiciones, rutinas y normas socialmente aceptadas, en donde se creaban los hábitos necesarios para la vida. Así, la escuela primaria se constituía en el lugar de encierro temprano para el niño, que instituía una forma de nombrarlo, de infantilizarlo, como el niño de primaria: 
(...) la vida social o educativa del niño recién comenzaba en el instante en que entraba a la escuela, ya que todas sus actividades anteriores competían sólo al hogar, o sea, su orientación e implementación les correspondían a los padres. De ahí que la información que se posee, en su gran mayoría, solo se limita al campo estrictamente educativo ya que el niño fuera de este ámbito no era materia de noticias (Cerda, 1984: 58).

Sin embargo, esto no significaba que la preescolarización de la infancia no se hubiese ido insinuando como un vestigio en la vida social de los años sesenta, ya que por ejemplo, se venían estableciendo ciertas condiciones que preparaban su aparición, véase, la preocupación generada por la ausencia de "(...) programas oficiales (...) que [presentaban] la irregularidad de que cada maestro [improvisaba] su propio programa (...)" (El Tiempo, 1960, 3 de enero. 2.500 Aulas Escolares Construirá el Gobierno Nacional en Este Año. p. 9), en los primeros atisbos de educación pre-escolar, así como, la creación de organismos de Estado como el Instituto Colombiano de Bienestar Familiar (ICBF) en 1968 y en 1969, que procuraban institucionalmente proteger a la niñez. Por consiguiente, debido a múltiples y complejas circunstancias de diverso orden (escolar, político, económico, social y cultural), la idea de preescolarizar a la niñez incursionó con mayor fortaleza para crear un esquema distinto al instaurado en el que «encerrar prematuramente» a la niñez, garantizaba por ejemplo, disminuir los niveles de deserción, repitencia y "ausentismo escolar primario [que] por motivos de salud, nutrición, temprana dedicación laboral” (El Tiempo,1969, jueves16 de enero. La primaria en trance difícil. p. 9), aspectos que se habían instalado como problemáticas escolares, y que precisamente, con la preescolarización infantil se pretendían resolver. El régimen de verdad instaurado empezaba a resquebrajarse para permitir que otros discursos funcionaran como verdaderos y otros entraran en decadencia. Estas discursividades propugnaban por una transformación educativa, por el mejoramiento "(...) en [la] calidad educativa (...) [a partir de] cambios en el área de plan de estudios, [en el] suministro de textos, equipos de enseñanza, ayudas audiovisuales, cursos de capacitación del personal en servicio, formación de especialistas etc." (Arizmendi Posada, 1970, 24 de Enero. "La estrategia de la transformación educativa. El Tiempo, p. 2), el nombramiento de maestros, la construcción de nuevas aulas escolares de primaria, el incremento de recursos económicos y materiales, la ex- pansión de los servicios educativos en todos los niveles y campos. Por ende, el país afrontó una eficaz y profunda transformación en el sector de la educación, que se materializó en la formulación, por ejemplo, del Plan Quinquenal Educativo, durante el gobierno del presidente Alberto Lleras Restrepo, con el que se buscaba:

Además de la intensiva construcción de escuelas y de la mayor capacitación de maestros (...) [garantizar] positivas realizaciones tanto en el nivel de la educación elemental como en la educación media (...). De manera concreta en la esfera primaria se [perseguía] el objetivo de suministrarla al ciento por ciento de los niños colombianos en edad escolar, para superar todas las deficiencias que en esta materia se han advertido hasta el presente y para hacer una realidad concreta del precepto constitucional que ordena la educación elemental gratuita y obligatoria (1969, martes 9 de diciembre. También en la educación. El Tiempo, p. 4A).

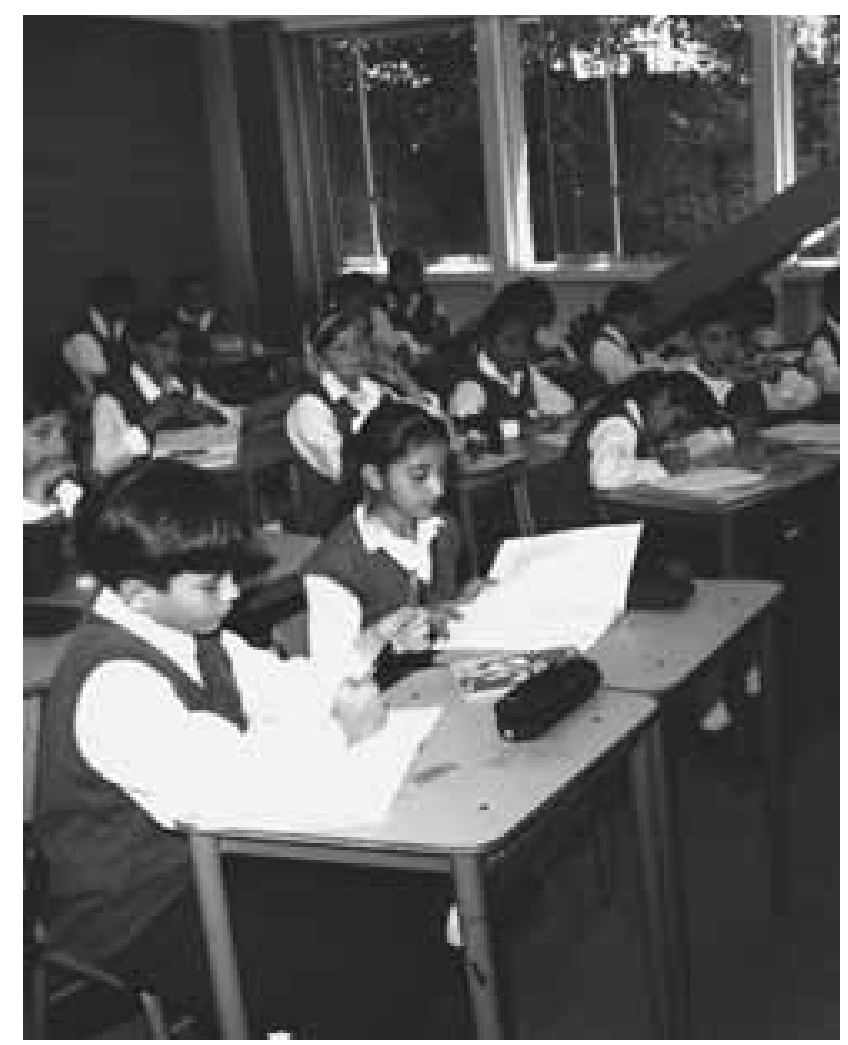


Lo anterior trajo entre otras consecuencias, que en la sociedad de la época, se enunciara la "necesidad" de atender a los niños, de lanzar un halo de protección sobre ellos ante su inocencia y lo quebrantable de su ser y considerar como un asunto ineludible, la previa escolarización como medida para evitar las posibles rutas de fuga de la escuela. En fin, la retórica educativa colombiana a finales de la década del sesenta empezaba a "metamorfosearse" para asumirse distinta, como un proceso de ampliación, transformación y modernización educativa, que consideraba que "estudiando más transformamos a Colombia" (Arismendi Posada, 1970. El Tiempo, sábado 24 de enero. La estrategia de la Transformación Educativa. El Tiempo, p. 2), condición que marcaba no sólo la vida social, sino que se constituía en el elemento dinamizador del proceso de expansión de la escolarización, que afectaba a todos los niveles de la enseñanza, afirma Martínez Boom (2004). Esta incursión se fundaba en el imaginario que comprendía que el acceso a la educación era la garantía para alcanzar el bienestar y crecimiento económico en los países:

El nuevo afán fue estimulado por el reconocimiento de las condiciones de carencia educativa que existía en ciertos países latinoamericanos, que nosotros caracterizamos como «bloqueo de la escolarización», frente a las cuales la única solución posible era expandir la escuela por todos los rincones de su geografía. Lo que estaba en juego era la puesta en marcha de la modernización social basada en el crecimiento y el desarrollo (Martínez Boom, 2004: 47).

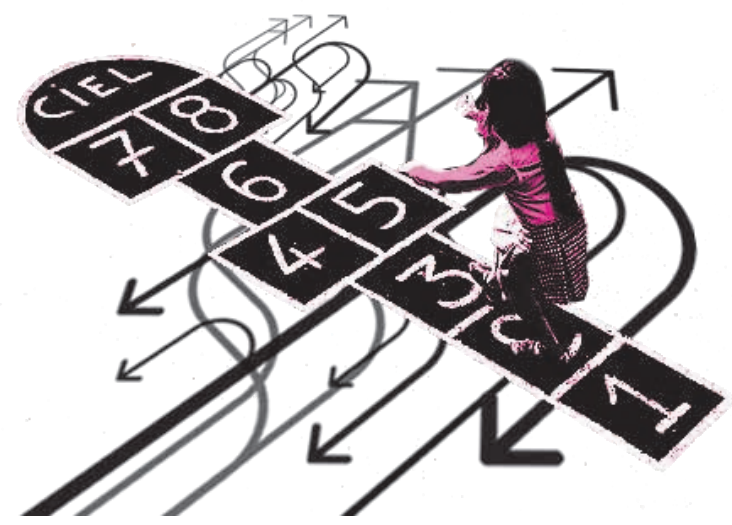

De esta manera, estas «políticas expansivas», «procesos de escolarización horizontal» ampliaron en forma significativa la cobertura, multiplicaron la población escolar tanto de estudiantes como [de] maestros, los recursos financieros, su cubrimiento y equipamiento entre otras acciones, señala Martínez Boom (2004). Paralelamente a esta difusión horizontal, se dio una «expansión en sentido vertical» en la que se incorporaron nuevas edades y niveles, como el preescolar al sistema educativo. El gobierno nacional empezaba a reconocer en ese momento, la importancia y el valor de la educación pre-primaria al insinuar mediante el decreto 1637 de 1960, la creación de una sección de educación preescolar como dependencia del Ministerio de Educación Nacional. Por consiguiente, la expansión educativa, no sólo constituyó un mecanismo para enfrentar la crisis mundial de ajuste macroeconómico sino que incursionó como una línea de fuerza para garantizar la superación de la «desatención» educativa a la niñez. El acceso a la enseñanza, entonces, se convirtió en un intento por democratizar la escuela, incorporando la idea sobre lo razonable que podría resultar incluir la enseñanza preescolar en el sistema para lograr una mayor igualdad de oportunidades en la vida, en la medida en que contribuiría a reducir las deficiencias sociales y culturales que padecían muchos niños. Así pues, la aparición del preescolar en la educación pública, se constituyó en un dispositivo que empezaba a potenciar las acciones emprendidas para mitigar las necesidades de los niños que se vivenciaban entonces. Con este acontecimiento, emergió una retórica discursiva que promulgaba que la educación preescolar debía estar al servicio de una autentica democratización, donde cada individuo tuviese las mismas posibilidades de desarrollarse y de tener éxito:

La expansión de la escuela se inició con el proyecto de universalización y democratización social, que buscaba homogeneizar bajo ciertos mínimos a la mayor cantidad posible de la población, y trataba de unificar -como de hecho lo hizo-, contenidos, recorridos y metas. En este sentido la escolarización masiva fue un proyecto político que comprometió a las clases dirigentes y al Estado, entendiendo la manera como éste, no sólo se ocupa de la gestión como tal, sino que también asume un papel crucial en la formación de la sociedad civil, visibilizando la importancia de la regulación social" (Martínez Boom, 2004). 
La mujer: «Una gran fuerza humanizante de la sociedad»: La pre-escolarización como sustituto del hogar

Hacía los años sesenta la concepción sobre la mujer comenzó a transfigurarse, instaurándose una imagen que la muestra como «fuerza humanizante de la sociedad» que proclamaba por una "revolución humana, (...) en la que no [se permitiera] la explotación y el engaño (...) que no [dejará] corromper [el] ambiente y poner en peligro a [los] hijos, en la que [se luchase] contra la inautenticidad y superficialidad de las relaciones humanas, en la que no [se tolerase] la guerra y la violencia como solución final a los conflictos entre los hombres" (Alzate A. M. La rebelión de las mujeres en E. U. Afrontan problemas del sexo. En todo caso serán más "agresivas", 1969. El Tiempo, p. 18). Este hecho incidió para que las Naciones Unidas promulgarán en 1975 el Año Internacional de la Mujer, época en la que "los más activos movimientos femeninos [aprovecharon] para manifestar (...) sus radicales puntos de vista" (Uslar Pietri, 1975, Jueves, 16 de enero. El año de la mujer. El Tiempo, p. 5A). De similar manera, profundos cambios (desarrollo urbano, precarización de la situación socioeconómica familiar, incorporación de la mujer (madre de familia) al mundo laboral en todos los niveles ocupacionales, entre otros), incidieron en la conformación familiar colombiana y en la asignación de roles y funciones de sus miembros, produciendo que en un alto porcentaje de hogares, en los que la figura femenina asumía "el control del hogar", las prácticas iniciales de habituación quedaran supeditadas, relegadas y desatendidas, tanto que a la niñez se le abandonaba y se le descuidaba en su adiestramiento e instrucción previa, fortaleciéndose así, la idea de "inventar" un ideario que respaldara la necesidad de la atención adecuada a los niños en edad pre-escolar. Hasta ese entonces, la concepción de mujer como « (...) pieza fundamental en la educación y formación de la primera infancia» (Cerda, 1984: 150 151), encargada en el hogar de disciplinar al niño tempranamente, empezó a resquebrajarse y esta "función social" empezó a ser asumida por otros agentes que la sociedad inventaría. Esta nueva condición social fue impulsada aún más con la aparición de ciertos discursos que proclamaban las pocas diferencias existentes entre "la educación de niños cuyas madres [trabajaban], y los hogares en [el] que la mujer [dedicaba] todo su tiempo a la educación de los hijos (...) Los estudios también [in- dicaban] que los niños que se [levantaban] en centros de educación infantil (...) [mostraban] por lo menos la misma capacidad que los niños de hogar» (Alzate, A. M., "La rebelión de las mujeres en E. U., afrontan problemas del sexo", p. 18, 1969, El Tiempo).

Con ello, se impelía con fuerza la idea de escolarizar tempranamente a los niños. La sociedad enfrentaba una fuerte disputa entre el reconocimiento de una niñez abandonada y la necesidad de expandir una aureola protectora sobre sí. En medio de esta tensión surgen políticas, instituciones, sujetos, discursos y lugares alrededor de la atención y cuidado, buscando cobijar a esa niñez que producto del nuevo rol de madre trabajadora se enunciaba como "abandonada", sin afecto y sin disciplinamiento inicial. Así pues, en el nuevo escenario emergente se debaten temas relacionados con los derechos de la mujer, su situación de injusticia social, su incorporación laboral y el hecho de que por ello, sus niños reciben cada vez menos atención en el seno familiar, en especial, por parte de ella. Ante estas circunstancias, ya el disciplinamiento de la niñez dejaba de ser un asunto exclusivo de la familia en sus primeros años para ser una responsabilidad de la sociedad en general, de las instituciones educativas, y posteriormente de los medios de comunicación; la madre trabajadora se veía obligada a consentir que la sociedad arrancase a los niños de la familia; la sociedad misma, ya no "confía" en ella para amoldar su espíritu, es inexorable entonces, crear una entidad distinta a la existente, para que lo escolarice e inculque en él los valores humanos y la motivación que se requiere para su desarrollo integral, es ahora, una institución que se preescolariza la que intenta dar a los pequeños la guía y la instrucción que con frecuencia descuida la familia. Así, la familia dejaba de disciplinar tempranamente para delegar a la escuela esta función. 
«La era del hambre y la edad de oro de la salud: Apuestas por derrotar a una sociedad injusta»: La pre-escolarización como estrategia de alimentación y salud

A mediados de la década de los setenta, el incremento en la desocupación de la población colombiana, incursionaba en la sociedad como una línea de fuerza que generaba que las condiciones de vida de la población fuesen precarias. Para enfrentar esta situación, el gobierno nacional emprendió a través del Plan Piloto Contra el Desempleo una serie de reformas que incluían la "revisión del sistema educativo para ajustarlo a las necesidades de desarrollo y a la estructura de la demanda futura del mercado (...) y (...) formuló políticas de población, entre las que se cuentan amplios programas para la planificación familiar" (Castellanos, "Plan contra el desempleo. Misión Internacional estudiará Programa de Gobierno", viernes 2 de enero, 1970, El Tiempo. p.p. 1A y 6A).

Unido a esto, se manifestaba cómo el vertiginoso desarrollo de la civilización industrial, el perfeccionamiento de los medios de producción y la explotación de la riqueza del suelo, hacían evidente "el drama de las carencias alimenticias que diezmaba sin misericordia a hombres, mujeres y niños" (Zapata Olivella, 1976, jueves 18 de enero. Plan 76 para la mala nutrición. El Tiempo, p. 5A); así mismo, la mala organización de los recursos alimenticios, preveía que al mundo le esperaba una «Era del Hambre», que podía prolongarse durante varios decenios y que podría llevar a verdaderas guerras por la subsistencia, se enuncia que "el mundo no tiene alimentos suficientes. Y cada día tendrá menos" (Escribano, 1975, domingo 12 de enero. ¿La Era del Hambre? El Tiempo, p. 5A). De otra parte, Planeación Nacional sostenía que "alrededor del 60 por ciento de los niños menores de cinco años presentaban algún grado de desnutrición, [mientras que] las investigaciones [demostraban] que el 30 por ciento de las familias [tenían] mala nutrición" (Ayala J, 1976, domingo 4 de enero. \$2.875 millones se invertirán en los planes de nutrición. El Tiempo, p. 6A). Adicionalmente, las deficiencias alimenticias, señalaban el Consejo Episcopal Latinoamericano (CELAM), el Fondo de Naciones Unidas para la Infancia (UNICEF) y el Secretariado Latinoamericano de CARITAS (SELAC), "constituían la causa principal de muerte en niños menores de cinco años en Colombia, una tasa de mortalidad, nueve veces mayor que la de los países desarrollados. Lo más lamentable de la situación (...) es que estos niños [morían] por causas que se [podían] prevenir, puesto que (...) la humanidad [contaba] con conocimientos y tecnologías (...) para proteger la vida y la salud de los niños" (CELAM, UNICEF, SELAC, 1988: 1), así, organizaciones de orden eclesiástico, acudían a criterios de otros discursos disciplinares y constituían verdades que se institucionalizaban en la vida social.

Con este hecho, irrumpió entonces el discurso alrededor del nivel de desnutrición y hambre que sufría la niñez, como una de las formas para medir el grado de justicia o inequidad imperante en la sociedad, voces como estas, influyeron como políticas de verdad y conocimiento para que la población de la época comprendiera la importancia de invertir en salud, nutrición y estimulación temprana en los primeros años de vida, lo que condujo a la vez, acciones como la intervención económica de la Cooperativa Americana de Remesas al Exterior (CARE) que en asocio con el ICBF adelantó programas de nutrición para niños y madres lactantes en todo el país. Sumado a esto, se diseñó un Plan Nacional de Alimentación y Nutrición, que consistió en la distribución y producción subsidiaria de alimentos y un Programa Nacional de Educación Nutricional que hizo parte del Sistema Nacional de Salud para campañas de nutrición (1975, viernes, 3 de enero. Alimentos a 600 mil niños suministrará CARE este año. El Tiempo, p. 6A). Había entonces que "nutrir al niño para «moldear» su carácter” (Popkewitz, 2006: 47). Paralelamente a la nutrición infantil, la preocupación por la salud de los niños fue incursionando como un asunto de interés social. En ese sentido, se vio cómo a comienzos de los setenta, se declaraba en Colombia la «Edad de Oro de la Salud Infantil», época en la que se formulaba que "Ios niños nacidos en esta década tenían una perspectiva de vida mucho más feliz que los de la generación anterior. [Ya que] nunca como ahora la ciencia [había] logrado tantas conquistas en bien de la salud infantil, hasta el punto de que se ha llamado la "edad de oro" a la época. Hoy los niños son más sanos, más fuertes y pueden esperar un provenir más seguro, no sólo por los alcances científicos y médicos, sino por la forma cada vez más consciente como padres y educadores comprenden sus necesidades en todos los campos" (El Tiempo, de enero. "Edad de oro de la Salud Infantil", domingo 19, 1969: 6). Además se declaraba a 1970, como "el año de la educación en el Distrito Especial" (refiriéndose a Bogotá), "por cuanto en él culminan, satisfactoriamente, los intensos esfuer- 
zos, de las anteriores administraciones locales (...) para dar acogida en las escuelas oficiales y gratuitas a todos los niños bogotanos en edad escolar" (CELAM, UNICEF, SELAC, 1988: 3). En consecuencia, la preocupación por el bienestar de los niños, en relación con la prevención de enfermedades, programas de salud, nutrición y educación, convoca a los gobiernos, al Fondo de las Naciones Unidas para la Infancia (UNICEF) y la Organización Mundial de la Salud (OMS), entre otras instituciones públicas y privadas, nacionales e internacionales, para que buscaran las estrategias que más impacto tuvieran para evitar muertes y enfermedades infantiles y promover el desarrollo integral del niño, factores que en los años setenta permitieron "medir (...) el grado de justicia o inequidad imperante en una determinada sociedad", (Valencia Jaramillo, 1976, miércoles 29 de diciembre. La sociedad injusta. El Tiempo, p. 9E).

\section{La ofensiva contra la pobreza, una tmanera de controlar a la población}

La ofensiva por disminuir los niveles de pobreza irrumpió en los años setenta, como una relación de fuerza para gobernar a la población colombiana. Esta condición se constituyó en "un asunto público, [en el que] el Estado [protegía] pero sobre todo [controlaba] la pobreza, que se [inscribía] de manera general en el problema del gobierno de la población (...)" (Martínez Boom, 2005: 144). Pero además, resaltaba cómo el intento por solucionar las condiciones económicas precarias, obligaban a los padres de familia a descuidar a sus hijos.

Como se observa, este fenómeno pone en evidencia que el abandono de niños era una actividad frecuente dada las condiciones de pobreza y miseria en las que vivía la población, que dinamizó el aumento de las solicitudes para la formación de casas con espacios para los párvulos, afirma Martínez Boom (2005: 142) e irrumpió para hacer posible la aparición de una nueva subjetividad, el niño preescolarizado. Así (como la escuela), el preescolar de la educación pública, le permitió al Estado, entre otras cosas, controlar la pobreza prematuramente: nació para atender, controlar, dominar, persuadir, convencer y encerrar a la niñez pobre, para «recluir la miseria tempranamente»:

(...) lo que aparece es una nueva regularidad en donde se dibuja con trazos cada vez más firmes una política de carácter totalizador para el recogimiento de niños pobres encerrando sus vidas en ocupaciones y ejercicios con los cuales se pretende desterrar sus "libres costumbres", corregirlos para acostumbrarlos a vivir en policía. Esta regularidad no elimina ni sustituye las otras prácticas y formas educativas" (Martínez Boom, 2005: 155).

Sumado a esta situación de pobreza, el Estado promovió la formulación de políticas de planificación familiar, señalando que "«ciertamente el costo de vida [era] muy alto para el alcance (...) de (...) casi [la] totalidad de los pobres y una inmensa mayoría de la clase media» afirmación que se [complementaba] con otros datos demasiado serios relativos a los ingresos de la población colombiana y a las condiciones precarias y difíciles para lograr el sustento, lo cual es un hecho, que será mucho más grave cuando la población se doble y la mesa no alcance para los comensales que llegarán en el futuro. Por estas consideraciones la planificación familiar [fue] una forma de aliviar al pueblo de los desposeídos de las aflicciones que traen el hambre y la miseria" (El Tiempo, 1976, sábado 3 de enero. Control Natal. p. 4A). Pero de similar forma, ciertos discursos en los que se establecían relaciones entre las condiciones económicas y el aprendizaje infantil, se introdujeron durante los setenta, precisamente para impeler la aparición de la preescolarización de la niñez. Como se advierte, la pobreza se instituyó como una fuerza que dinamizó la preocupación por la atención de los niños y el surgimiento de la preescolarización infantil. "Más concretamente la pobreza, de manera azarosa, reorganiza, dispara y saca a flote la nueva problemática de la población [como] fenómeno social que era necesario [someter] a un régimen o hacerla gobernable mediante un conjunto de pautas de crianza e instrucción con los cuales se pudiera gobernar el alma y controlar el cuerpo". (Martínez Boom, 2005: 135). Es decir, la invención de la preescolarización se convirtió en un dispositivo para controlar tempranamente al niño, su libertad, su actuación e independencia, pero también en algún modo, para que el Estado sometiera la pobreza que irrumpía en el país.

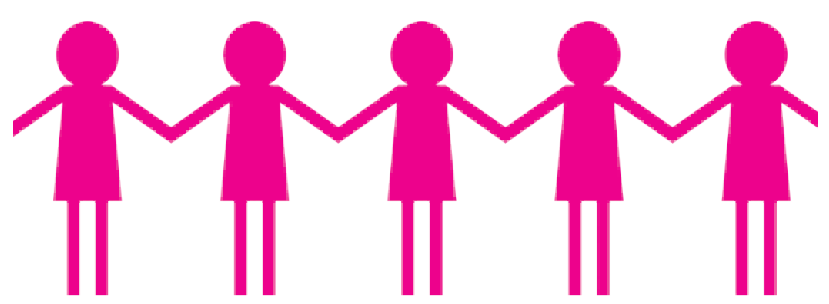


«Contra la explosión demográfica, educación»: Intento por controlar y reducir los nacimientos

A comienzos de los años setenta el control sobre el aumento demográfico se constituía en una preocupación no sólo a nivel mundial, sino a nivel del país, al punto que se organizaban e instalaban certámenes en los que se discutían y planeaban las acciones y políticas a desarrollar para enfrentar esta situación. EI IV Congreso Nacional de Planificación en 1969, en el que se anunciaba cómo "Ios tiempos [estaban] muy difíciles para hacerse cargo de lo que en las clases populares se llama «una boca más» (...) [expresando que el] excesivo crecimiento demográfico, [producía] el natural desequilibrio entre las carencias de esa población y los recursos disponibles del Estado para atender las necesidades en trabajo, educación, asistencia social y cultural, etc.", que demandaba la sociedad ( "Se instaló IV Congreso Nacional de Planificación", miércoles 3 de diciembre, 1969, El Tiempo, p. 5A). Más adelante con la Conferencia Mundial de Población, reunida en Bucarest en 1975, se afirmó que, "no hay ningún remedio efectivo y práctico para tan grave amenaza (...). No [se sabe] si es urgente el problema de la explosión demográfica y de la escasez de alimentos y materias primas" (Uslar Pietri; 1975, Jueves, 16 de enero. El año de la mujer. El Tiempo, p. 5A). Sin embargo, el gobierno nacional decidió afrontar esta situación, aumentando la implementación de programas de planificación familiar, tomando en cuenta las recomendaciones de la jerárquica eclesiástica colombiana en torno a la fecundidad, como un intento por disminuir además, las precarias condiciones económicas y el abandono infantil:

La adopción de estos programas [era] necesaria ante el alto índice de nacimientos que acrecienta a las familias y [que hacían] nugatorios la mayoría de planes para mejorar la situación social y económica de los colombianos. [Con ellos se buscaba] corregir la ignorancia de las gentes respecto de la planificación familiar y disminuir el elevado número de abortos originados por la falta de información. Tras una serie de estudios en los que participaron médicos demógrafos, el ministerio de Salud, e incluso representantes de la Iglesia, se llegó a la conclusión de que por carencia de conocimientos miles de mujeres ponen en peligro su salud y acrecientan la ilegitimidad. Sin avasallar los principios de moral, el plan fue concebido [a] favor de la paternidad responsable (...) no [como] un hecho meramente biológico sino [como] un compromiso con la familia y la sociedad" (El Tiempo, 1970, sábado 3 de enero. Aumentarán programas de planificación familiar. Basados en recomendaciones de la Iglesia. p. 2).

Por su parte, en opinión de expertos del Departamento Nacional de Planeación se expresaba la existencia de "(...) una alta proporción de parejas que [deseaban] planificar su descendencia y [manifestaban] un deseo cada vez mayor, de conocer mejor los métodos y procedimientos" (El Tiempo, 1970, Aumentarán programas de planificación familiar. Basados en recomendaciones de la Iglesia. Sábado 3 de enero. p. 2). Así, durante la década de los setentas la preocupación por el control natal incursionó en la sociedad de la época como un discurso más para solidificarse como una práctica legitima que se enfrentaba a los modos de comprender la situación demográfica hasta el momento:

Cuando se habla de los peligros que puede ofrecer para el futuro el desbordado crecimiento de la población, suele confundirse el control de la natalidad y la planificación familiar. La primera en su justa acepción es coercitiva, en el sentido de que el Estado la impone como una obligación definitiva y determinada en las Leyes, como sucede en numerosos países. En Colombia no existe ni existirá jamás, por lo menos mientras se mantengan los principios tutelares de nuestra Carta Constitucional, que ante todo reconoce, respeta y hace respetar la libertad de conciencia. Precisamente en esta norma se fundamenta la planificación familiar que, en esencia, no es otra cosa que un acto cuya decisión corresponde única y exclusivamente a la determinación de las parejas, sin que medie ninguna intervención por parte del Estado. Cada hombre y cada mujer tienen de acuerdo con estos principios, el derecho a escoger el número de hijos que consideren conveniente entregar al mundo (El Tiempo, 1976. Control Natal. Sábado 3 de enero. p. 4A).

Contrario a lo anterior, la iglesia colombiana, en cabeza del Cardenal, en su momento enunció cómo:

(...) todas las campañas antinatalistas, [condenándolas] como criminales (...) correspondían a un fuero propio del Estado, en desarrollo de la libertad de conciencia que, entre otras cosas es una de las conquistas más importantes logradas por el pueblo colombiano a lo largo de su historia. 
Así como el Estado reconoce los principios de la Iglesia Católica, sin tratar de intervenir en sus dogmas, así también la jerarquía que la representa debería guardar idéntica reciprocidad al Estado, cuando acepta, recomienda y aún estimula la planificación familiar, teniendo en cuenta su obligación de velar por el futuro de las generaciones (El Tiempo, 1976. Control Natal. Sábado 3 de enero. p. 4A).

Así, entraban en disputa dos líneas de poder, dos instituciones, que pretendían legitimar sus prácticas socio-culturales, racionalidades y saberes, con efectos de verdad, para solidificarse como prácticas socialmente aceptadas, confrontación en las que se desplazaban y deslegitimaban otras, que visibiliza lo que había permanecido oculto, como por ejemplo, el aborto, que se ejercía como una conducta camuflada en la población y que suscitó expresiones de rechazo, exclusión, negación y censura por parte del Papa Pablo VI quien instaba a la humanidad a:

(...) a amar a los niños e indirectamente [reafirmaba] la oposición de la Iglesia Católica Romana al aborto (...) «los niños son el centro de nuestro interés» (...) «el cristianismo dice más: que la vida de todo niño es sagrada bien sea que todavía viva en el vientre materno, o que ya entre a nuestras casas, escuelas o iglesias» (...) niños «que sufren y están hambrientos» merecen atención especial" (El Tiempo, 1970. Rechazo de la Iglesia al aborto, ratifica el Papa. Lunes 5 de enero. p. 10).

De esta forma, se evidenció, de una parte, que el control natal se convertía en una práctica social y educativa para enfrentar ciertos problemas demográficos, y de otra, una batalla entre la Iglesia y el Estado, en la lucha por instaurar su posición frente a las políticas de planificación familiar, configurando un discurso alrededor del crecimiento demográfico, que se instituyó como una verdad, transfigurando el régimen de verdad impuesto, en la pretensión de modernizar e instituir en el país, "una sociedad del tipo industrial (...) [ya que] lo único que se puede afirmar es que: la modernización y la baja fecundidad coexisten" (El Tiempo, 1978. Revolución demográfica en Colombia. Martes 12 de diciembre. p. 8B). En concreto, como medida para controlar el fenómeno demográfico en el país, se diseñó una serie de programas que extendían la información y servicios médicos sobre planificación familiar, procurando disminuir la fecundidad y, por ende, el alto número de nacimientos y así reducir la tasa y ritmo de aumento de la población. Dichas medidas produjeron en la población posiciones encontradas, entre quienes pensaban que la planificación familiar interfería en el control de la natalidad, lo cual representaba una posición coercitiva por parte del Estado ante la decisión y derecho de las familias a decidir su conformación familiar y quienes apoyaban la intervención del gobierno en la planificación familiar como una forma de aliviar al pueblo de las aflicciones que ocasionaban el hambre y la miseria pues, "la explosión demográfica, que se [reflejaba] en el extraordinario crecimiento de las ciudades (...) un país no [podía] llevar a cabo tal expansión de su población sin sufrir las consecuencias; sin aumentar considerablemente su desempleo, sin que [faltaran] escuelas y servicios de higiene, sin crisis administrativa y judicial, en fin, sin sufrir el desorden social que [produjo] la inseguridad personal" (Trías, 1977, sábado, 10 de diciembre. La utilidad de la planificación familiar. El Tiempo, p. 5A), circunstancias que incursionaron como líneas de fuerza, que entraron en conflicto, para enunciar la importancia de centrar la atención social sobre la niñez.

\section{La preocupación \\ por una niñez indefensa: Una cuestión social}

Los planteamientos acerca del cuidado, atención y protección a la infancia, como los mecanismos de preservación humana, se instalaron como verdades en la sociedad, como «nuevas narrativas de salvación de la infancia» (Popkewitz, 2006: 34), para validar, legitimar y aceptar ciertas prácticas, discursos y maneras de actuar frente a la niñez, que se caracterizaba por ser autorregulada, responsable de sus prácticas, comportamientos y rutinas; que se autocorrige, autoevalúa y autodisciplina. De este modo, la imagen de niño controlado, observado, el escolar de la primaria, empezaba a ser desplazado como centro de interés educativo, para permitir que una nueva condición histórica-subjetiva se institucionalizara. El cuerpo infantil sumiso, débil y dependiente había mutado hacia una subjetividad diferente que se construyó en la contemporaneidad de la vida social. Ahora es importante regular las actitudes del niño, por tanto, las nuevas normatizaciones, prácticas y patrones que se configuran en la escuela habrían de propender por: 
Lograr un desarrollo integral del niño en los aspectos físico, psicosocial, ético e intelectual; lograr que el niño amplíe los conocimientos de su realidad social y material, valorando los aspectos positivos de su cultura; desarrollar la capacidad de iniciativa, la imaginación y el espíritu de investigación y descubrimiento, a fin de establecer relaciones creadoras en su grupo social; [cuyos objetivos particulares eran] (...) desarrollar en el niño habilidades y destrezas que le ayuden a ser más productivo en su trabajo de transformación y creación; lograr que el niño a través del juego y el trabajo colectivo, enriquezca las posibilidades de conocimiento, expresión y comunicación" (Acosta, Concha \& Garcés, 1978: 2-3).

Por ende, las investigaciones de la época comenzaron a generalizar la idea que durante los primeros cinco años de vida se determinaba no sólo la supervivencia sino el momento en que se adquiría el potencial básico, mental y afectivo que condicionaba el futuro del ser humano. Esta mirada sobre la niñez como porvenir de la humanidad se instauró socialmente, visibilizando que «un desarrollo deficiente en la primera infancia, afectaba al individuo durante toda su vida, ocasionando a veces daños irreversibles» (CELAM, UNICEF y SELAC, 1988: 2), y resaltando que "los primeros años de vida [son importantes] para fraguar el porvenir y desarrollar más plenamente la personalidad del niño. Con esta nueva imagen sobre la niñez, se infantiliza aún más la sociedad, para poner en marcha un proceso a través del cual se comienza a amar, proteger y atender a los niños, ubicando a la institución escolar en un papel central, así, infantilización y escolarización aparecen en la modernidad como dos fenómenos paralelos y complementarios, (Caldeiro, 2005: párr. 12). La «infantilización» de la sociedad se va configurando como un dispositivo que constituye en su interior relaciones de fuerzas, subjetividades, que van a permitir la enunciación de una niñez distinta, de unas prácticas sociales, jurídicas, económicas y políticas que se diferencian de las ya establecidas.

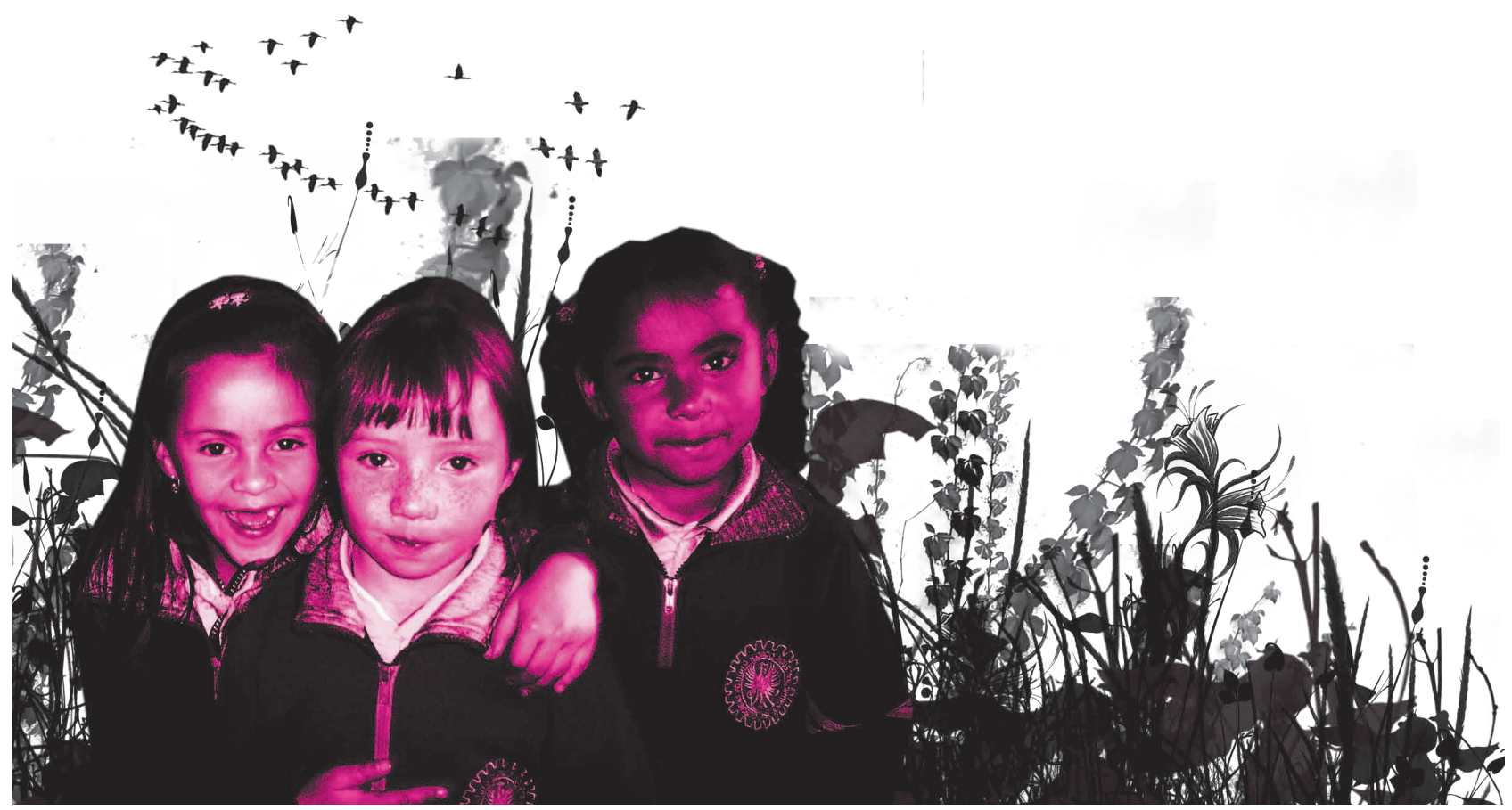




\section{Observando la conducta del niño}

A finales de los años sesenta en Colombia, la preocupación por observar periódicamente la conducta de la niñez escolarizada, ubicada en la escuela primaria, se mantuvo como uno de los ideales de la escuela, a través de este dispositivo de disciplinamiento, el maestro lograba comprender, orientar y guiar al niño en el progreso del aprendizaje, fomentando así, su desarrollo armónico y su integración a la vida social. Con la observación objetiva, el niño era permanentemente vigilado por la sociedad a través del maestro, quien asumía el rol de «custodio» para corregir aquellos comportamientos, actitudes y hábitos considerados como no deseables por la sociedad, se manipulaba el cuerpo infantil, se "educaba", se le acondicionaba para obedecer y se le daba forma requerida. Pues, se trataba de un cuerpo dócil, maleable, que permitía un control minucioso y un disciplinamiento (Carassai, 1998: párr. 20). En estas condiciones, la escuela adoptaba la forma de una institución de protección y regulación de la vida y los comportamientos infantiles, que comprendía que entre más temprano se iniciara este «control», mayores serían las posibilidades de lograr resultados sobre la infancia. Así, la observación se convirtió en un mecanismo de disciplinamiento arraigado sobre la niñez curricularizada, a través de la cual se controlaba la adquisición de aquellos patrones aprobados por el mundo de los adultos, ya que es legitimado como:

(...) el método para conocer mejor la Sicología infantil. En efecto, la observación de los niños ofrece muchas posibilidades de aprendizaje (...) permite descubrir las causas que motivan diversas formas de conducta y apreciar las diferencias individuales del desarrollo y crecimiento (...) para hacer un buen estudio del crecimiento y desarrollo y dadas las cualidades dinámicas de éstos se precisa la observación objetiva y la evaluación periódica de la conducta de los niños. Sólo en esta forma pueden los maestros, aumentar su conocimiento y su comprensión de los niños como seres humanos en desarrollo (Ministerio de Educación Nacional (MEN, 1965: 10).

Más aún, con este dispositivo de vigilancia se buscaba prever en qué dirección se movía el niño para amonestarlo, tomar precauciones, hacerlo maleable, legitimar modos de proceder, determinar los caminos y el «accionar coercitivo", como medio que impulsaba el compor- tamiento correcto. Esto significaba comprender al niño para «desactivarlo», ya que una vez conocido opondría poca resistencia, es por esto que las misiones de reconocimiento son las condiciones sine qua non para forzar al enemigo a rendirse, diría Bauman (2007: 9). Este poder «panóptico» es decir, vigilancia constante y cuidado permanente a cambio de pérdida de libertad y autonomía, según Bauman (2003: 40-41), «ata a los subordinados al lugar en el que pueden ser vigilados e instantáneamente castigados por cualquier quebrantamiento de la rutina. Pero también ata a sus vigilantes al lugar desde el que tienen que llevar a cabo su vigilancia y justo castigo". La dominación es una cuestión de «vinculación» entre niño observado y el maestro vigilante que lo custodia. En este sentido, parafraseando a Foucault, el preescolar de la educación pública, asumió la función de «colocar fuera de circulación» a los niños, en la medida en que instituyeron prácticas preescolarizadas procedentes de la escolarización primaria y adaptadas a las nuevas condiciones de existencia de una infancia preescolar, que los convertía en fiables y neutralizados; pero además, admitía la función de «integración», pues, confería aquellos modelos deseables de conducta y elementos de comportamiento que la sociedad legitimaba. Es preciso señalar, que esta imagen del preescolar como lugar de vigilancia temprana de los niños, «fábricas de obediencia de estilo panóptico» Bauman (2003: 52), se van a desmantelar posteriormente, "augurando un gran salto adelante en el camino de una mayor libertad para el individuo" (Bauman, 2003: 52).

\section{Hacia la construcción de políticas sociales a favor de la niñez}

Para finales de los setenta, la niñez se constituía en una subjetividad fundamental de las políticas de Estado, en ellas se enunciaba la importancia del derecho a la educación, la asistencia y bienestar social, unido al suministro de la escuela, la nutrición escolar, la protección infantil, medios para asegurar el cuidado de los niños. En concordancia con esto, se promulgaron múltiples normas que se comportan como hitos que surgen en una época dada, con los que se busca atender a la niñez desprotegida. Entre esas disposiciones legales, ya en el año 1976, se había publicado el decreto 088, con el que se amplía aún más el «anillo 
salvador» que resguardaba a la infancia. Se proclamaba también, «El Año Internacional del Niño», por parte de las Naciones Unidas en 1979, alrededor del cual se permitió el diseño de emblemas y logotipos que simbolizaban la preocupación mundial por la niñez. Del mismo modo, se insinuaba con potencia que en todos los Estados americanos era necesario establecer un nuevo derecho, de carácter oficial, eminentemente tutelar y no punitivo cuyas normas estuvieran consignadas en un sólo cuerpo legal llamado "Código" o "Estatuto" del niño, del menor o de la familia, que sólo en la década de los setenta en Colombia, irrumpieron con fuerza para posibilitar la constitución el Código del Menor, en el que se consignaban los comportamientos aceptables socialmente y las sanciones a adelantar en caso de que los niños "infringiesen" la ley:

(...) efectivamente, el año pasado en la subdirección de asistencia legal del Instituto Colombiano de Bienestar Familiar (...) se preparó el proyecto de Código del Menor, que se trata de un documento de trascendental importancia, en el que se consigna la política nacional de protección materno-infantil, dirigida a las familias colombianas, y en particular a la protección de las gentes menos favorecidas (...). Con este código se gusta brindar atención integral, que procure el equilibrio en el desarrollo mental, físico y emocional, de esta célula básica de la sociedad, que es la familia (...). Un paso inicial se dio en Colombia en el año de 1946 cuando se expidió la ley 83, "orgánica de la defensa del niño", en la que se incluye la necesidad de proteger al niño y a la madre desde la etapa de la gestación (El Tiempo, 1978. Derecho de familia. El Código del menor. Lunes, 23 de enero p. 1B).

Es precisamente esta consideración de niñez desprotegida y vulnerable la que permitió, entre otras líneas de fuerza, que se cobijara al niño con el velo de la preescolarización, en este lugar a cambio de su libertad estaría seguro de muchos de los males que afectan al mundo. Entre tanto, la Organización de las Naciones Unidas para la Educación, la Ciencia y la Cultura -UNESCO-, financió un plan cuatrienal en Colombia con el fin de perfeccionar la planificación y desarrollo de las actividades educativas y culturales del país. El acuerdo contemplaba, la planificación, administración e investigación educativa, la capacitación docente; el desarrollo científico y tecnológico; y el desarrollo cultural, acciones que en conjunto buscaban mejorar la calidad de la educación nacional en el nivel preescolar, básico, primario y secundario, medio e intermedio profesional, mediante planes de capacitación y perfeccionamiento docente, en el reglón de capacitación docente.

Como se observa, la atención acerca de la gratuidad y la obligatoriedad de la educación en el nivel elemental incursionó en la sociedad como una fuerza que se va a traducir en la atención en salud y en la prevención del trabajo infantil. A partir de entonces, los niños menores de 6 años comenzaron a ser incorporados a las políticas públicas como una forma de consolidar el enfoque desarrollista de la época. Con ello surgen las primeras manifestaciones de la expansión vertical, que consiste en incorporar a la escolaridad amplios sectores de la población que hasta entonces no eran objeto de la escuela ni mantenían con ella un vínculo directo. Añade el autor, que lo que hoy se llama educación inicial no ha sido siempre lo mismo; socialmente han existido formas variadas de ocuparse de la primera infancia. En distintos momentos, estas formas han tenido diferentes denominaciones, que corresponden a maneras también diversas de entender y configurar sus

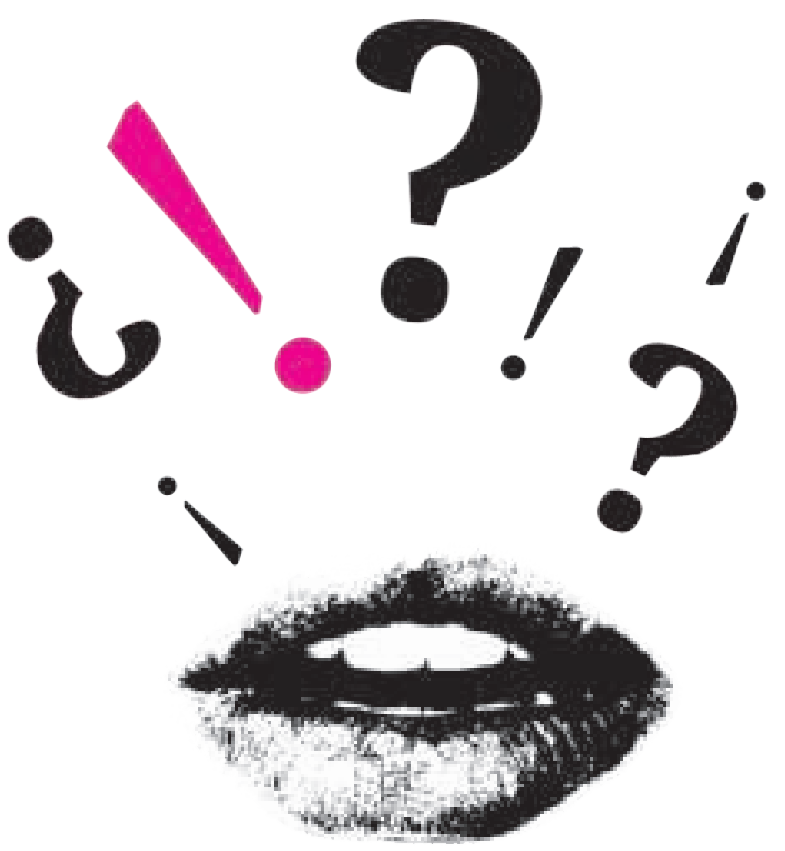


prácticas, la ubicación en el sistema y la función que cumplen dentro de él. En otras instancias han estado por fuera del sistema educativo, guardando casi total independencia de su dinámica. Pero, por efecto de la expansión vertical de la escuela se han ido incorporando progresivamente como el primer nivel de escolarización. De otra parte, a mediados de los años setenta, el niño de preescolar de la educación pública va dejando de ser un vestigio que invade, para ubicarse dentro del campo escolar como una subjetividad a la que, a través de diversas prácticas, se le promueve y estimula el desarrollo físico, afectivo y espiritual, su integración social, su percepción sensible y el aprestamiento para las actividades escolares:

(...) la formación en el niño de hábitos y actitudes de independencia y autosuficiencia, de solidaridad, de afecto y de respeto, de investigación e inventiva, de apreciación y creación de belleza, de amor a la naturaleza y al trabajo, de enfrentamiento constructivo y positivo de las dificultades (El Tiempo, 1978, jueves 26 de enero. El juego base de la educación preescolar. p. 6D).

Es evidente como se va configurando como una práctica pedagógica que enuncia de modo distinto a la niñez escolarizada. El niño de preescolar dócil, obediente y dependiente va decayendo en la vida escolar para transfigurarse, para permitir la emergencia de un niño «abierto, móvil y flexible». Por lo visto, una nueva subjetivación infantil se va constituyendo, un cuerpo infantil preescolarizado que se forma en el desarrollo de "habilidades y destrezas que le ayuden a ser más productivo en su trabajo de transformación y creación; lograr que el niño a través del juego y el trabajo colectivo, enriquezca las posibilidades de conocimiento, expresión y comunicación" (El Tiempo, 1978, jueves, 26 de enero. El juego, base de la educación preescolar. p. 6D).

\section{«¿Cuándo empieza la educación institucional del niño?»: El valor de la educación pre-primaria}

Como se ha venido planteando, la sociedad de los años setenta, comenzó a considerar necesario envolver a la infancia en un «cerco de seguridad» para salvaguardarla de los peligros. Con lo que se hizo imprescindible crear un mundo privado con instituciones adecuadas e instalaciones acordes a las necesidades de los niños, donde se les brindaba protección, instrucción y educación, pero ante todo, fueron sumergidos prematuramente en esa condición de encierro para asegurar la adquisición de aquellas normas, comportamientos y disciplinas que la sociedad demandaba, con lo que se garantizaba auxiliar a una niñez abandonada, desamparada y desasistida. Por ende, la preescolarización pública de los niños como mecanismo de protección infantil prematura, fue incorporándose como un dispositivo dentro del marco social, instituyéndose como un acontecimiento y como expresión de cambio de una época que infantilizaba a la sociedad. Conviene subrayar además, que el niño preescolarizado no tiene rostro, no está encarnado, es una rareza que da cuenta de una época, es un conjunto de prácticas, de discursos, de maneras de visibilizar a la niñez; es un modo de proceder de la sociedad en un momento determinado, que emergió como un "fenómeno curioso" diría Badinter (1981: 12-13) de una lucha de fuerzas discursivas y no discursivas. La concepción de niño de preescolar de la educación pública en Colombia, es un «descubrimiento» propio de la contemporaneidad, «un devenir que se escapa a la historia», cuyas condiciones de existencia empezaron a configurarse recientemente, distintas a las que configuraron al niño de la educación primaria.

Al hallarse estas líneas de fuerza en conflicto permanente en torno a la atención de ese niño que se preescolarizaba, que enunciaba la época como desvalido, desprotegido y a quien era necesario incluir en el sistema educativo, se introduce el reconocimiento del «valor de la educación pre-primaria» por parte del Gobierno Nacional. Es así como, mediante el decreto orgánico No. 1637 de 1960, se instauró la Sección de Educación Pre-escolar como dependencia del Ministerio de Educación, en el marco de la reorganización del Ministerio de Educación Nacional además de establecer sus funciones. Dado que a esta sección "se le asignaron, básicamente, funciones normativas y de orientación, ante la imposibilidad económica de asumir la responsabilidad de este servicio, cuando no le ha sido posible al gobierno cumplir cabalmente la obligación constitucional de la enseñanza primaria gratuita y obligatoria" (decreto No. 1637 de 1960). No sin antes mencionar en dicha normatividad, que una de las finalidades de la educación preescolar, entre otras, consistía en preparar al niño para el paso del hogar a la escuela primaria. Así mismo, en el curso de la década del setenta, la proliferación de importantes investigaciones en el área de la educación temprana destacaba el aporte de este tipo 
de escolarización al éxito escolar, enunciando fuertemente como «la base fundamental de la formación del hombre [radicaba] en los primeros pasos que se [dieran] en sus primeros años de (...) educación. Así, la educación preescolar empezaba a constituirse como:

La primera y decisiva etapa de acción pedagógica en la formación intelectual y afectiva del educando, en la que [era] importante atender integralmente a los niños, proyectando la acción educativa a la comunidad, en la que los maestros se [convertían] en orientadores prácticos de la iniciativa privada en el campo de la educación preescolar (Decreto 1576 de 1971).

Por ende, en esa idea de cobijar a la mayor cantidad de niños dentro del sistema (social, educativo, político), se promulgó el decreto 1576 de 1971, en el cual se expresaba la importancia de ampliar los servicios de educación preescolar en el país. A su vez, y como un mecanismo para impulsar la preescolarización temprana, en diciembre de 1975 el Comité de Coordinación y Promoción para el Desarrollo Integral del Niño (...) autorizó a su presidente para invitar a la Fundación Bernard Van Leer, institución holandesa sin ánimo de lucro a enviar una misión al país. La Fundación adelanta una sustantiva labor internacional, especialmente, relacionada con el desarrollo integral del niño de las áreas marginadas por medio de donaciones a proyectos de innovación tendientes a buscar innovación educativa. De esta manera, se instaura una nueva capa histórica, con poderes, discursos e instituciones en movimiento, en la que la atención sobre el niño de la escue-

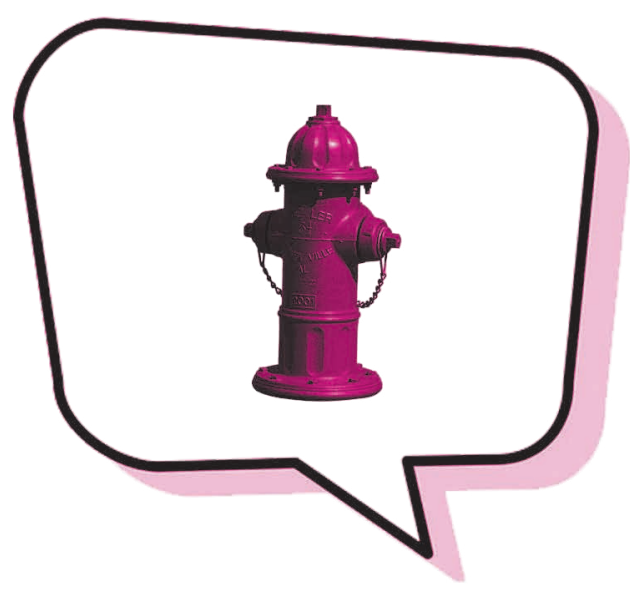

la primaria se desplazaba hacia el niño preescolarizado emergente.

\section{Para niños de preescolar... Maestros de preescolar}

De la mano de esa niñez preescolarizada se fue configurando, un nuevo poder, una subjetividad distinta encargada de vigilar, someter y adiestrar, precisamente a aquel niño preescolarizado, un maestro de preescolar responsable no sólo de la atención, cuidado y establecimiento de las prácticas de disciplinamiento infantil en un ambiente de encierro sino de la constitución de nuevas maneras de concebir a la infancia escolarizada. Así pues, con el transcurso de los acontecimientos y situaciones características de la época, al verse ampliados los niveles y abrir el sistema a la atención de esos niños de preescolar, se hizo necesario un maestro de preescolar en la educación pública. Lo que no quiere decir que no hubiera existido previamente, al contrario éste fue renombrándose, reconfigurándose hasta llegar a enmarcarse y obtener la representación en la categoría del maestro de preescolar que hoy día se concibe. En la década de los sesenta, con el decreto 1955 de 1963 al reorganizarse la educación normalista se declaró que "las escuelas normales [podrían] tener (...) cursos de formación de maestros para educación preescolar (...) el jardín infantil, como campo de aplicación y demostración para la educación preescolar". También se mencionaba en este decreto, que una de las finalidades de la formación del maestro era "que [pudiera] comprender y orientar la conducta del niño, guiarlo en el progreso de aprendizaje, [fomentando] su desarrollo armónico y [favoreciendo] su integración a la vida social". Es así que a mediados de los años setenta se alzan voces que aclamaban que "los niveles de preescolar exigían maestros idóneos. «Maestros especializados en Educación Preescolar»:

Veinte maestras, las primeras que en el país [recibían] el título en educación pre-escolar, [recibiendo] su grado en el presente mes de diciembre en el Instituto Colombiano de Educación pre-Escolar, Incepre (...) La doctora Victoria Bosso Herrera, directora del Incepre, hizo hincapié en la importancia de los 6 primeros años de vida y definió al pre-escolar como "la promesa del futuro y materia prima del cambio o desarrollo". Recordó a sus alumnas cómo las fallas de algunas sala-cunas, guarderías y jardines 
infantiles, en ocasiones imposibles de evitar, producen traumas que pueden deformar la personalidad del menor (...) recalcó sobre la responsabilidad contraída por las graduandas de sumarse al esfuerzo que realiza el Gobierno y algunas entidades privadas para extender al mayor número de niños los beneficios de los programas institucionales de atención al pre-escolar (El Tiempo, 1975, sábado, 4 de enero. Primeras graduadas en educación preescolar. p. 11A).

No obstante, durante 1976, época de "profundos cambios en la educación", con el decreto 088 de 1976 el Ministerio de Educación Nacional incluyó formalmente la educación preescolar como primer nivel del sistema educativo formal. Por su parte, el ámbito universitario reconocía que debía centrar su atención en este aspecto, dado que en 1976, por primera vez se le otorga estatus universitario a la formación de maestros de preescolar, tanto así que ya en 1978 se creara el programa de Licenciatura en Educación Preescolar adscrito a la Facultad de Educación de la Universidad Pedagógica Nacional. Hecho que profesionalizó a dichos maestros e incidió al disminuir la brecha existente entre la educación pública y privada, que venía ofreciéndose como preparación para la escuela primaria. A comienzos de los años ochenta entonces, momento en el que la niñez preescolarizada insinúa una metamorfosis, en la que se desplaza el disciplinamiento por el autogobierno, sufre similar condición sufre el maestro preescolarizado. En consecuencia, "se dio inicio a (...) programas de formación profesional, con un enfoque que se sustenta en la pedagogía y en el desarrollo infantil" (Jaramillo de Certain, 2003: párr. 11). Así pues, el maestro encargado del cuidado, de guiar e instrumentalizar al niño de preescolar a través de "planes de estudios [que eran] netamente técnicos y el enfoque de formación estaba dirigido a la ejecución de tareas" (Jaramillo de Certain, 2003: párr. 11), se transmutaba en una subjetividad diferente, pues, las condiciones de existencia de la nueva niñez preescolarizada así lo requerían.

\section{Epílogo de un exordio}

Ya en los años noventa, la idea de un nuevo sujeto preescolarizado se instituye como una fuerza de poder, un saber y una subjetivación, introducida en la escuela para transformarla, para hacer de ella otra institución distinta. El diagrama de fuerzas y la estratificación histórica, son diferentes. El niño de preescolar de la educación pública, ha dejado de ser una rareza para consolidarse como una realidad histórica inventada por la sociedad e institucionalizada para permanecer. Así:

Los sujetos escolares dóciles y disciplinados dejan paso a un nuevo tipo de sujeto escolar, el sujeto escolar siempre en curso; esto es, un tipo de población escolar-tanto docente como alumno- que ocupa la mayor parte de su tiempo y de sus energías tratando de readaptarse a las nuevas y cambiantes exigencias del entorno, así como procurando estar en constante proceso de actualización, formación continua y aprendizaje permanente (...) El sujeto escolar siempre en curso -ya vaciado de cualquier raíz social, esto es, convertido en individuo desocializado y entidad autónoma- se erige en responsable absoluto de su movimiento perpetuo (...) (Gómez \& Jódar, 2003: 58).

De antemano, la nueva realidad social emergente que invade, transforma precisamente las condiciones históricas de la época, las relaciones de saber, poder y subjetivación institucionalizadas, y se introduce en la escuela para transfigurarla en una organización escolar distinta, así, nuevas condiciones se establecen para "cobijar" su permanencia allí (horarios, planes de estudio, saberes y maestros distintos). A lo cual, la educación preescolar, parafraseando a Martínez Boom (2005: 155-156), crea unas formas de regulación del tiempo y el espacio que afecta las prácticas (el tipo de ejercicios como la repetición, lo consuetudinario... los horarios), con lo cual (...) no tiene en sus comienzos como función fundamental la educación o el conocimiento o ilustración de los [niños], sino una tarea mucho más pedestre de amoldamiento de los pobres y especialmente de los niños pobres, proceso que con el tiempo tiende a generalizarse a vastos sectores de la población. De igual manera, contribuyeron en esta institucionalización de la preescolarización infantil, las reformas, principios y normas establecidas en la Ley General de Educación, 115, en la que se señalaron lineamientos para transformar la escuela, la enseñanza y el aprendizaje, promoviendo la participación ciudadana y democracia participativa y la incorporación de la educación preescolar como nivel obligatorio de la educación formal. Con la instauración del niño de preescolar de la educación pública como realidad emplazada, las prácticas pedagógicas procuraron contribuir el desarrollo integral y armónico de los niños y niñas de 5 a 6 años de edad, posibilitando su interacción física, reflexiva y afectiva con los objetos 
de la naturaleza, de la cultura, con otras personas, para que de este modo, desarrollara su autonomía, creatividad y la expresión en todas sus manifestaciones. Los niños preescolarizados son llamados entonces "a asumir la responsabilidad sobre ellos mismos, a retomar su vida como proyecto personal en el que ellos se convierten en los [propietarios] de su propio yo, modelando su vida a través de actos de elección" (Gómez \& Jódar, 2003: 59). As entonces, el cuerpo infantil sumiso, débil y dependiente ha mutado, ha quedado atrás, en el "olvido" y una nueva subjetividad propia de la contemporaneidad se construye, poniendo en evidencia, múltiples cuestionamientos alrededor del fin de la escuela, de la infancia moderna, la «desinfantilización» de la vida social contemporánea. Al respecto, Mariela Carassai (1998: párr. 31) señala como:

La fuerza del discurso pedagógico ha declinado, por lo que en la actualidad asistimos, aparentemente, a una decadencia de la pedagogía moderna: el fin de la infancia caracterizada por el quiebre del modelo de dependencia y heteronomía respecto del adulto (...). Esta crisis se reconvierte, ahora es el niño un ser independiente, un niño activo, que toma decisiones y asume sus actos y que trabaja con sus propias reglas y ritmos. Dos son las concepciones que ponen en tela de juicio a la concepción de infancia moderna: la "infancia hiperrealizada" y la "infancia desrealizada" (Narodowski, 1999: citado en Carassai, 1998). La primera se trata de una infancia de la realidad virtual (Internet, cable, etc.), donde prevalecen la satisfacción inmediata y la demanda de la inmediatez. La segunda, es la infancia de la realidad real, que vive en la calle, que es autónoma e independiente, que está excluida de la Internet y también excluida institucionalmente. Una infancia de la realidad virtual "armónica y equilibrada" versus la infancia de la realidad real, violenta y marginal. Este quiebre en la concepción de infancia moderna, nos obliga a discutir y reflexionar acerca de si puede hoy la pedagogía formar "el niño del mañana.

Como se observó, el niño de preescolar de la educación pública, no es una realidad natural u obvia que ha estado presente siempre en la vida social, sino más bien una invención histórica que fue constituida en cierto momento de la humanidad. Como novedad que irrumpe, puede mutar, cambiar su posición o desaparecer del campo social y escolar, ya que así como al principio, no tuvo importancia alguna en la vida social, se fue ubicando con fuerza, alterando verdades, transformado prácticas, discursos y subjetividades. Por consiguiente, la concepción de niño de preescolar de la educación pública en Colombia, es un «descubrimiento» propio de la contemporaneidad, «un devenir que se escapa a la historia», cuyas condiciones de existencia empezaron a configurarse recientemente, distintas a las que configuraron al niño de la educación primaria.

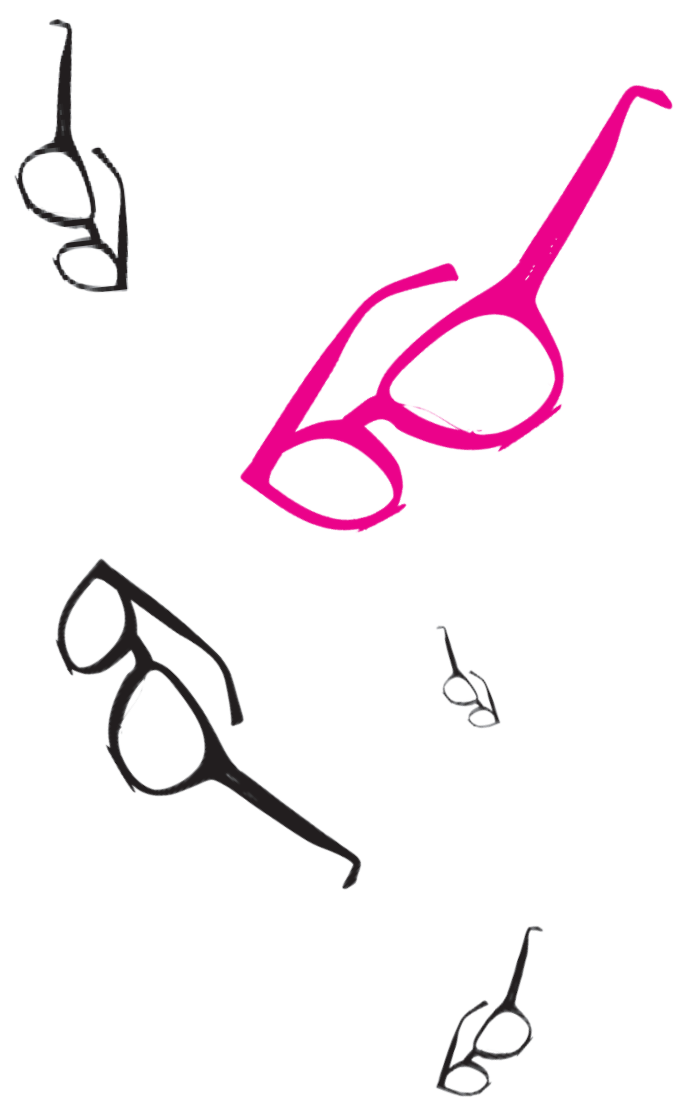




\section{Bibliografía}

\section{Fuentes Primarias}

Acosta, G; Concha, M. y Garcés, N. (1978). Guía práctica de actividades para niños de 3 a 6 años. Ministerio de Salud Pública, Bogotá: ICBF.

Burgos, C. E. (1987). Desarrollo del Niño y algunos temas relacionados con el preescolar. Currículo de Preescolar, Documento No. 2. Bogotá: MEN.

CELAM, UNICEF, SELAC. (1988). Manual de Capacitación para el trabajo por la supervivencia y el desarrollo infantil en la parroquia. Bogotá: Autores.

MEN. (1965). Guías didácticas para maestros de primaria. Bogotá: Autor

\section{Artículos de Prensa}

Abad Gómez (1976). “La amenaza de la despoblación”. EL TIEMPO, lunes 20 de diciembre, p. 5A.

Alzate, A. M. (1969). "La rebelión de las mujeres en E. U. Afrontan problemas del sexo. En todo caso serán más agresivas". EL TIEMPO, p. 18.

Arizmendi Posada, O. (1970). "La estrategia de la transformación educativa”. EL TIEMPO, 24 de enero, p. 2.

Ayala J. (1976). "2.875 millones se invertirán en los planes de nutrición”. EL TIEMPO, domingo 4 de enero, p. 6 A.

Castellanos. (1970). "Plan contra el desempleo. Misión Internacional estudiará Programa de Gobierno".

EL TIEMPO. viernes 2 de enero, pp. $1 \mathrm{~A}$ y $6 \mathrm{~A}$.

EL TIEMPO. (1960). “2.500 aulas escolares construirá el gobierno nacional en este año”. p. 9, 3 de enero.

EL TIEMPO. (1969). “La primaria en trance difícil”. p. 9, jueves 16 de enero.

EL TIEMPO. (1969). "Edad de oro de la salud infantil”, domingo 19 de enero.

EL TIEMPO. (1969). “Se instaló IV Congreso Nacional de Planificación”. p. 5A, miércoles 3 de diciembre.

EL TIEMPO. (1969). “También en la educación”. p. 4, martes 9 de diciembre.

EL TIEMPO. (1970). "Aumentarán programas de planificación familiar. Basados en recomendaciones de la Iglesia". p. 2, sábado 3 de enero.

EL TIEMPO. (1970). "Rechazo de la Iglesia al aborto, ratifica el Papa”. p. 10, lunes 5 de enero.

EL TIEMPO. (1975). "Alimentos a 600 mil niños suministrará CARE este año”. p. 6A, viernes 3 de enero. 
EL TIEMPO. (1975). "Primeras graduadas en educación preescolar”, p. 11A, sábado 4 de enero.

EL TIEMPO. (1976). "Control Natal". p. 4A, sábado 3 de enero.

EL TIEMPO. (1978). "Derecho de familia. El código del menor". p. 1B, lunes 23 de enero.

EL TIEMPO. (1978). "El juego, base de la educación preescolar”. p. 6D, jueves 26 de enero.

EL TIEMPO. (1978). "Revolución demográfica en Colombia”. p. 8B. martes 12 de diciembre.

Escribano (1975). “¿La Era del Hambre?”. EL TIEMPO, p. 5A, domingo 12 de enero.

Trías. (1977). "La utilidad de la planificación familiar". EL TIEMPO, p. 5A, sábado 10 de diciembre.

Uslar Pietri, A. (1975). El año de la mujer. EL TIEMPO, p. 5A. jueves 16 de enero.

Valencia Jaramillo. (1976). La sociedad injusta. EL TIEMPO, p. 9E, miércoles 29 de diciembre.

Zapata Olivella. (1976). Plan 76 para la mala nutrición. EL TIEMPO, p. 5A, jueves 18 de enero.

\section{Fuentes secundarias}

Álvarez, A. (2002). Enfoque arqueológico - genealógico. Orientaciones metodológicas para la lectura de fuentes primarias. Universidad Pedagógica Nacional, Grupo de Historia de la Práctica Pedagógica. Bogotá.

Álvarez, A. (2002). "Los niños de la calle: Bogotá 1900-1950". En: Historia de la Educación en Bogotá. Tomo Il, Serie Investigaciones, Bogotá.

Álvarez-Uría, F.; Varela, J. (1999). Estrategias de poder. Barcelona: Paidós.

Badinter, E. (1981). ¿Existe el amor maternal? Barcelona: Editorial Paidós-Pomaire

Bauman, Z. (2003). "Comunidad. En busca de seguridad en un mundo hostil”. Temas para el siglo XXI. Madrid: Siglo XXI Editores.

Bauman, Z. (2007). La Sociedad Sitiada. Buenos Aires: Fondo de Cultura Económica.

Cerda Gutiérrez, H. (1984). Problemática del niño colombiano. Centro de Enseñanza Desescolarizada. Bogotá: Universidad Santo Tomás.

Gómez, L.; Jódar, F. (2003). "Foucault y el Análisis Sociohistórico: Sujetos, saberes e instituciones educativas". En: Revista Educación y Pedagogía, Facultad de Educación, número 37, volumen 15, Medellín: UA.

Martínez Boom, A. (2004). De la escuela expansiva a la escuela competitiva. Dos modos de modernización en América Latina. Convenio Andrés Bello. Barcelona: Anthropos-Editorial, Barcelona Laertes Educación. 
Martínez Boom, A. (2005). La escuela pública: del socorro de los pobres a la policía de los niños. Foucault, la pedagogía y la educación. Pensar de otro modo. Colección Pedagogía e Historia. Cooperativa, Editorial Magisterio, Bogotá.

Narodowski, M. (1993). Infancia y poder. Conformación de la pedagogía moderna. Buenos Aires: Editorial Aique.

\section{Fuentes electrónicas}

Caldeiro, G. P. (2005). La infancia, una construcción de la modernidad. En: educacion.idoneos.com/index. php/119539.

Carassai, M. (1998). El niño del mañana. ¿Quiénes son los niños hoy? En: Contexto Educativo. Revista Digital de Educación y Nuevas Tecnologías, No. 29, Año V, Argentina. En: http://www.contexto-educativo.com.ar/2003/5/nota-02.htm.

Jaramillo Certain, L. (2003). Antecedentes históricos de la educación preescolar en Colombia. Universidad del Norte. Instituto de Estudios Superiores en Educación. Barranquilla. Revista de Reflexión Socio Educativa. Diciembre- abril. No. 2, p. 17-25. En: http:// www. ylang-ylang.uninorte.edu.co:8080/.../AntecendentesHstoricosEducacionColombia. pdf.

Popkewitz. (2006). Infancia, Modernidad y Escolarización: Nacionalidad, Ciudadanía, Cosmopolitismos y «los Otros» en la constitución del sistema educativo norteamericano. En: González, Faraco. (2002). Infancia y escolarización en la modernidad tardía. Universidad Internacional de Andalucía. Ediciones Akal. Madrid. En: http://www. books.google. com.co/books?isbn=8446016036...

\section{Leyes, decretos y otras disposiciones legales}

Decreto 1637 de 1960. Por medio del cual se reorganiza el Ministerio de Educación Nacional y se determinan sus funciones.

Decreto 1710 de 1963. Por el cual se adopta el Plan de Estudios de la Educación Primaria Colombiana y se dictan otras disposiciones.

Decreto 1955 de 1963. Por el cual se reorganiza la educación normalista.

Decreto 1576 de 1971. Por el cual se amplían los servicios de educación pre-escolar en el país.

Decreto-Ley 088 de 1976. Por el cual se establece el nivel preescolar como el primero de la educación formal. 